\title{
Job block concept in two stage specially structured Flow shop scheduling to minimize the total waiting time of jobs
}

\author{
Dr. Deepak Gupta ${ }^{1}$ and Bharat Goyal ${ }^{2}$
}

\begin{abstract}
The present paper studies job block concept in specially structured two stage flow shop scheduling in which processing times are associated with respective probabilities. It is assumed that the maximum of expected times on first machine is less than or equal to the minimum of expected times on second machine. The objective of the study is to get optimal sequence of jobs in order to minimize the total waiting time of the jobs by taking two of the jobs as a group job through iterative algorithm. The algorithm is made clear by numerical example.
\end{abstract}

Key words- Waiting time of jobs, Flow shop scheduling, Processing time, Job block.

\section{INTRODUCTION}

Today's global markets and instant communications mean that customers expect high-quality products and services when they need them, where they need them. Organizations, whether public or private, need to provide these products and services as effectively and efficiently as possible. The total waiting time of jobs is defined as the sum of the times of all the jobs which was consumed in waiting for their turn on both of the machines. There are some papers in the literature of scheduling theory which consider the waiting time to be important for scheduling the jobs on the machines. Job block means to give priority of one job over another. Minimization of total waiting time of jobs can be calculated in the flow shop scheduling problem where the maximum of expected times on first machine is less than or equal to the minimum of expected times on second machine.

The problem discussed here is wider \& practically more applicable and has significant use of theoretical results in process industries or in the situations when the objective is to minimize the total waiting time of jobs. The concept of equivalent job for a job block is significant when the situations of giving precedence of one job over another arise, may be for the intention of improving productivity or by virtue of some scientific constraints.

\section{Literature Survey}

The fundamental study has been done by Johnson [1] to find optimal solution using heuristic algorithm for $\mathrm{n}$ jobs 2 and 3 machines flow shop problem. Ignall and Schrage [2] developed branch and bound

\footnotetext{
${ }^{1}$ Department of Mathematics Maharishi Markandeshwar University, Mullana (Ambala), Haryana , India

${ }^{2}$ Department of Mathematics Maharishi Markandeshwar University, Mullana (Ambala), Haryana , India
} 
algorithms for the permutation flow shop problem with makespan minimization. Lockett et. al. [3] studied sequencing problems which involves sequence dependent changeover times. Maggu \& Dass [4] introduced the equivalent job concept for job block in scheduling problems. Singh T.P. [5] extended the study by introducing various parameters like transportation time, break down interval etc. The work was further developed by Gupta J.N.D. [6], Rajendran C. et. al.[7], Singh T.P. et.al. [8]-[9]. Further Narain L., Gupta D. et.al. [10] made an attempt to minimize the rental cost of machines including job block through simple heuristic approach. Singh V. [11] put his efforts to study three machine flow shop scheduling problems with total rental cost. Further Gupta D. [12] studied minimization of Rental Cost in Two Stage Flow Shop Scheduling Problem, in which Setup Time was separated from Processing Time and each associated with probabilities including Job Block Criteria.

Recently Gupta D. \& Goyal B. [13] studied optimal scheduling for total waiting time of jobs in specially structured two stage flow shop problem processing times associated with probabilities. The present paper is an extension of the study done by Gupta D. \& Goyal B. [13] by introducing the job block concept.

\section{PROBLEM FORMULATION}

Let $\mathrm{p}$ jobs be processed through two machines $\mathrm{M}$ and $\mathrm{N}$ in the order $\mathrm{MN}$. Job $\mathbb{I}(\mathbb{1}=1,2,8, \ldots \ldots \mathrm{B})$ has processing time $\mathrm{M}_{\mathrm{i}}$ and $\mathrm{N}_{\mathrm{i}}$ on each machine respectively assuming their respective probabilities $\approx$ and $t_{i}$ such that $0, a_{1} \leq 1 ; 0, t_{1} \leq 1 \& \Sigma \Sigma_{1}-\Sigma_{1}=1$. Let an equivalent job $a$ is defined as $(k, m)$ where $k m$ are any jobs among the given $\mathrm{p}$ jobs such that job koccurs before job $\mathrm{m}$ in the order of job block (k, $\mathrm{m}$ )

\begin{tabular}{|c|c|c|c|c|}
\hline Job & \multicolumn{2}{|c|}{ Machine M } & \multicolumn{2}{|c|}{ Machine $\mathbb{N}$} \\
\hline I & $\mathrm{M}_{i}$ & $s_{i}$ & $\mathbb{N}_{i}$ & $t_{i}$ \\
\hline 1. & $\mathrm{M}_{1}$ & $s_{1}$ & $\mathbb{N}_{1}$ & $t_{1}$ \\
\hline 2. & $\mathrm{M}_{2}$ & $s_{2}$ & $\mathrm{~N}_{2}$ & $t_{2}$ \\
\hline 3. & $\mathrm{M}_{3}$ & $s_{n}$ & $\mathrm{Na}$ & $t_{3}$ \\
\hline$\cdot$ & & . & & . \\
\hline . & . & . & & · \\
\hline $\mathrm{p}$. & $M_{p}$ & $s_{p}$ & $\mathrm{~N}_{p}$ & $t_{p}$ \\
\hline
\end{tabular}

Table 1 : MATHEMATICAL MODEL OF THE PROBLEM IN MATRIX FORM

Then our problem is to find an optimal schedule $\mathrm{S}$ of all the jobs which minimize the total waiting time for all the jobs including job block concept.

\section{Assumptions}

1) $p$ Jobs are processed through two machines $\mathrm{M} \& \mathrm{~N}$ in the order $\mathrm{MN}$ i.e. no passing is allowed.

2) $\Sigma \nabla_{1}=\Sigma+n=1$

3) A job is an entity i.e. even though the job represents a lot of individual part, no job may be processed by more than one machine at a time.

4) It is given to sequence k jobs $\left\|_{2}\right\|_{k} \ldots \ldots \|_{k}$ as a block or group job in the order $\left(\|_{1}, l_{2} \ldots \ldots k_{k}\right)$ showing priority of job $h_{1}$ over $\hat{j}_{2}$ etc.

5) Jobs may be held in inventory before going to a machine.

Lemma 1. Let $\mathrm{p}$ jobs be processed through two machines $\mathrm{M}, \mathrm{N}$ in order $\mathrm{M} \mathrm{N}$ with no passing allowed. Let job $\mathbb{I}(\mathbb{1}=1,2,8, \ldots, \mathrm{p})$ has processing times $\mathrm{M}_{\mathrm{i}}$ and $\mathbb{N}_{\mathrm{i}}$ on each machine respectively assuming their respective probabilities $\Sigma_{i}$ and $t_{i}$ such that $0 \Sigma_{1} \leq 1 ; 0 \leq t_{1} \leq 1 \leq \Sigma_{1}-\Sigma z_{1}=1$. Expected processing 
times are defined as $\mathrm{M}_{\mathrm{i}}=\mathrm{M}_{1} * \Sigma_{1} \quad \mathrm{~N}_{1}=\mathrm{N}_{1} * t_{1}$ satisfying expected processing times structural relationship:

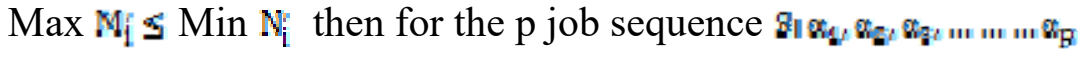

$\mathrm{T}_{\alpha_{p} \mathbb{N}}=\mathrm{M}_{\sigma_{1}}^{*}+\mathbb{N}_{\alpha_{1}}^{*}+\mathbb{N}_{\alpha_{2}}^{*} \ldots+\mathbb{N}_{\alpha_{\sigma}}^{*}$

Where $T_{a \mathbb{N}}$ is the completion time of job $\mathrm{a}$ on machine $\mathrm{N}$

Proof. Applying mathematical Induction hypothesis on p:

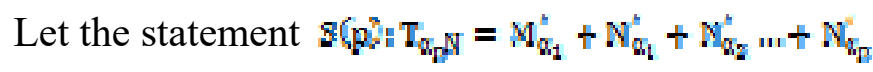

$\mathrm{T}_{\gamma_{1} \mathrm{MI}}=\mathrm{M}_{\mathrm{\gamma}_{1}}^{\mathrm{z}}$

$\mathrm{T}_{\mathrm{u}_{1} \mathrm{E}}=\mathrm{M}_{\mathrm{v}_{1}}^{n}+\mathrm{M}_{\mathrm{w}_{1}}^{\prime}$

Hence for $p=1$ the statement $₫(1)$ is true.

Let for $p=k$, the statement $s(k)$ be true, i.e.,

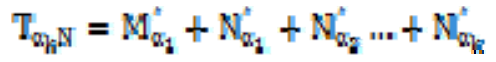

Now,

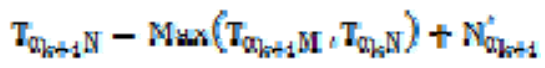

As $\operatorname{Max} \mathrm{M}_{\mathrm{i}} \leq \mathrm{M} m \mathrm{~N}_{\mathrm{i}}$

Hence

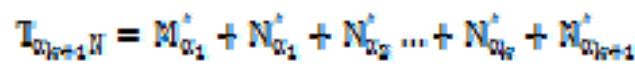

Hence for $p=k+1$ the statement $8(k+1)$ holds true. Since $S(p)$ is true for $p=1 p-k p=k+1$, and $k$

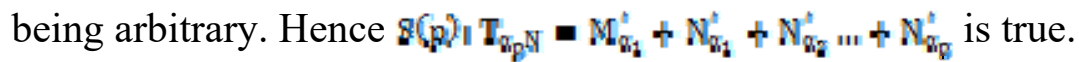

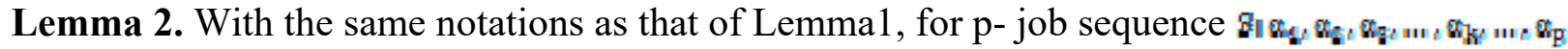

$W_{a_{1}}=0$

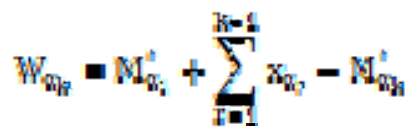

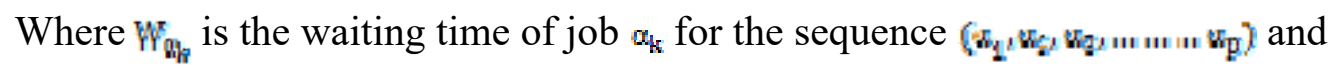

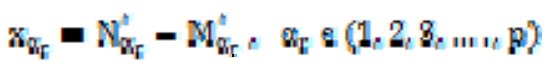

Proof. $W_{\alpha_{1}}=0$

$W_{\alpha_{k}}=\operatorname{Max}\left(T_{\alpha_{k}} \mathrm{MH}, T_{\alpha_{h-1} \mathrm{~N}}\right)-\mathrm{T}_{\alpha_{k} \mathrm{MI}}$

$=M_{\sigma_{1}}^{k}+N_{\sigma_{1}}^{k}+N_{\sigma_{2}}^{k}+N_{\sigma_{k-1}}^{k}-M_{\sigma_{1}}^{k}-M_{\sigma_{2}}^{k}+M_{\sigma_{k}}^{k}$ 
$-M_{r_{1}}^{n}+\sum_{i=1}^{k-1}\left(w_{r_{i}}\right)-M_{n_{k}}^{n}$

Theorem 1. Let $\mathrm{p}$ jobs be processed through two machines $\mathrm{M} \mathrm{N}$ in order $\mathrm{MN}$ with no passing allowed.

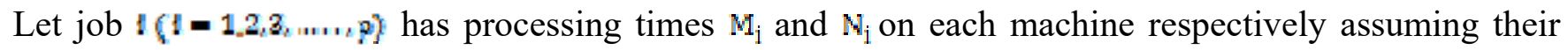

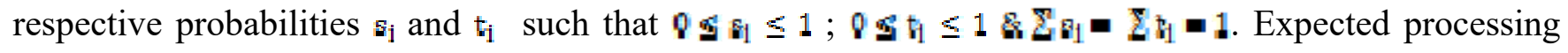
times are defined as $\mathrm{M}_{\mathrm{i}}=\mathrm{M}_{1} * \varepsilon_{1} \mathrm{~N}_{\mathrm{i}}=\mathrm{N}_{1} * \mathrm{t}_{\mathrm{s}}$ satisfying expected processing times structural relationship:

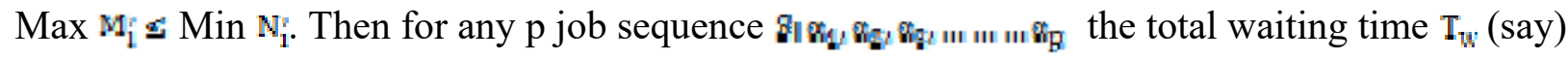

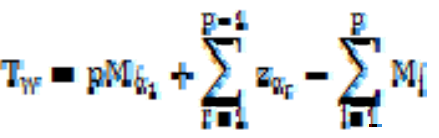

$z_{\gamma_{F}}=(p-\eta) x_{\gamma_{F}} ; \gamma_{i} \theta(1,2,8, \ldots, p)$

Proof. From Lemma 2 we have

$$
W_{\sigma_{4}}=0
$$

$k=2, k-1=1$

$W_{\mathrm{vg}_{2}}=\mathrm{M}_{\mathrm{w}_{1}}^{*}+\sum_{\mathrm{r}=1}^{1} \mathrm{x}_{\mathrm{w}_{\mathrm{r}}}-\mathrm{M}_{\mathrm{wg}}^{*}$

$k=3, k-1=2$

$w_{Q_{Q}}=M_{Q_{1}}^{*}+\sum_{\tau=1}^{2} x_{\sigma_{r}}-M_{Q_{I}}^{*}$

Continuing in this way

$\mathrm{k}=\mathrm{p} k-1=\mathrm{k}-1$

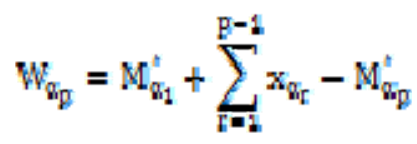

Hence total waiting time

$$
\begin{aligned}
& \mathrm{T}_{\mathrm{W}}=W_{\mathrm{Q}_{1}}+W_{Q_{\mathrm{g}}}+W_{\sigma_{\mathrm{Q}}}+\cdots+W_{Q_{\mathrm{Q}}}
\end{aligned}
$$

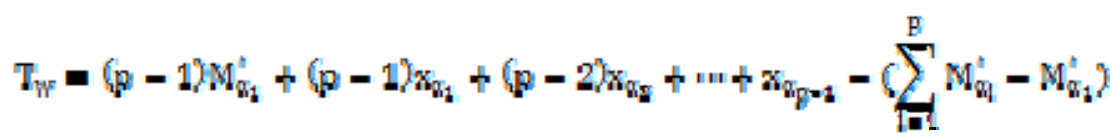

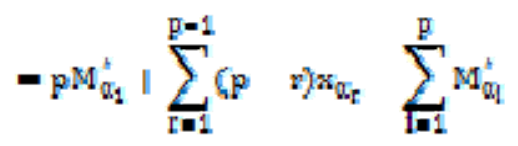

\section{Equivalent Job Block Theorem}


Theorem 2. In processing a schedule $s=(1,2,3, \ldots, \mathrm{p})$ of $\mathrm{p}$ jobs on two machines $\mathrm{M}$ and $\mathrm{N}$ in the order $\mathrm{MN}$ with no passing allowed. A job $\mathbb{f}(\mathbb{1}=1,2,3 \ldots \mathrm{p})$ has processing time $\mathrm{M}_{\mathrm{i}}$ and $\mathrm{N}_{\mathrm{i}}$ on each machine respectively. The job block $(\mathrm{km})$ is equivalent to the single job a (called equivalent job $a$ ). Now the processing times of job $a$ on the machines $\mathrm{M}$ and $\mathrm{N}$ are denoted respectively by $\mathrm{M}_{w} \mathrm{~N}_{\alpha}$ are given by

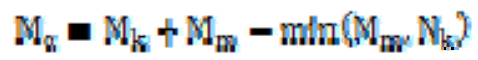

$\mathrm{N}_{\alpha}=\mathrm{N}_{\mathrm{K}}+\mathrm{N}_{\mathrm{m}}-\min \left(\mathrm{M}_{\mathrm{m}} \mathrm{N}_{k}\right)$

The proof of the theorem is given by Maggu P.L. and Dass G. [4].

\section{ALGORITHM}

To obtain optimal schedule we proceed as follows:

Step 1: Define expected processing times $\mathrm{M}_{1}$ and $\mathrm{N}_{1}^{z}$ on machine $\mathrm{M} \& \mathrm{~N}$ respectively as follows:

(i) $M_{1}-M_{1} * \varepsilon_{1}$

(ii) $\mathrm{N}_{1}=\mathrm{N}_{4} * \mathrm{t}_{1}$

$\operatorname{Max} \mathrm{M}_{\mathrm{i}} \simeq \operatorname{Min} \mathrm{N}_{\mathrm{i}}$

Step 2: Take equivalent job $\alpha=(\mathrm{km})$ and define processing times using equivalent job block theorem and replace the pair of jobs $\left(\mathrm{k}_{\mathrm{e}} \mathrm{m}\right)$ in this order by the single job.

Fill up the values in the following table:

\begin{tabular}{|c|c|c|c|}
\hline Job & Machine M & Machine N & \\
\hline I & $\mathbf{M}_{i}$ & $\mathbf{N}_{\mathrm{i}}^{\mathrm{z}}$ & $\mathrm{x}_{1}=\mathrm{N}_{1}-\mathrm{M}_{\mathrm{i}}$ \\
\hline 1. & $\mathrm{M}_{1}^{2}$ & $\mathrm{~N}_{1}^{\prime}$ & $\mathrm{x}_{1}$ \\
\hline 2. & $\mathrm{Mg}$ & $\mathrm{Mi}_{\mathrm{i}}$ & $\mathrm{x}_{\mathrm{z}}$ \\
\hline 3. & $\mathrm{M}_{3}$ & $\mathrm{~N}_{3}^{2}$ & $x_{\mathrm{g}}$ \\
\hline . & · & . & · \\
\hline$\alpha$ & $\mathrm{M}_{\alpha}^{\alpha}$ & $\mathrm{N}_{\alpha}^{\alpha}$ & $\mathrm{x}_{\mathrm{\alpha}}$ \\
\hline . & . & . & . \\
\hline r. & $\mathrm{M}_{r}$ & $\mathrm{~N}_{\mathrm{r}}^{\mathrm{r}}$ & $x_{\mathrm{r}}$ \\
\hline
\end{tabular}

Table 2

Step 3: Arrange the jobs in increasing order of $x_{i}$.

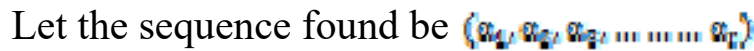

Step 4: Find $\operatorname{mln}\left\{\mathrm{M}_{1}\right\}$

Now two cases arise:

If $\left.M_{\delta_{1}}=m / n M_{i}\right\}$ then schedule according to step 3 is the required optimal sequence

If $M_{\delta_{1}} \neq \operatorname{minf} M_{i}$ then go to step 5 
Step 5: Consider the different sequence of jobs $S_{1}, S_{2} s_{p}, \ldots, s_{1}$. Where $S_{1}$ is the sequence obtained in step 3 , Sequence $s_{i}(1-2,8, \ldots \ldots, \eta)$ can be obtained by placing $f^{\text {th }}$ job in the sequence $S_{1}$ to the first position and rest of the sequence remaining same.

Step 6: Fill up the values in the following table

\begin{tabular}{|c|c|c|c|c|c|c|c|c|}
\hline Job & Machine & Machine & & \multicolumn{5}{|c|}{$z_{1 r}=(p-r) x_{1}$} \\
\hline I & $\mathrm{M}_{\mathrm{i}}^{\prime}$ & $\mathbf{N}_{\mathbf{1}}$ & $x_{1}=N_{1}-M_{1}$ & $r=1$ & $r=2$ & $\mathrm{r}=3$ & .......... & $p=p-1$ \\
\hline 1. & $\mathbf{M}_{1}$ & $N_{1}$ & $\mathrm{~s}_{1}$ & $z_{11}$ & $z_{12}$ & $z_{12}$ & …........ & $z_{4 \mathrm{~B}-1}$ \\
\hline 2. & $\mathrm{M}_{2}$ & $\mathrm{~N}_{2}$ & $x_{2}$ & $\mathrm{z}_{21}$ & $\mathrm{z}_{22}$ & $z_{22}$ & $\ldots \ldots \ldots$ & $z_{\mathrm{B}-4}$ \\
\hline 3. & $\mathrm{Mg}_{\mathrm{g}}$ & $N_{9}$ & $\mathrm{x}_{9}$ & $z_{31}$ & $z_{n}$ & $z_{n}$ & .......... & $z_{n \mathrm{n}-1}$ \\
\hline . & & . & . & $\cdot$ & - & & . & $\cdot$ \\
\hline p. & $\mathrm{M}_{p}$ & $N_{p}^{p}$ & $\mathrm{x}_{\mathrm{p}}$ & $z_{z 1}$ & $z_{p z}$ & $z_{p z}$ & $\ldots$ & $z_{\mathrm{p} p=1}$ \\
\hline
\end{tabular}

Table 3

Step 7: Calculate the total waiting time $T_{\mathrm{w}}$ for all the sequences $S_{1}, S_{\mathrm{Z}_{1}} \mathrm{~S}_{\mathrm{g}, \ldots \ldots} \mathrm{S}_{\mathrm{r}}$ using the following formula:

$\mathrm{T}_{\mathrm{w}}=\mathrm{pM} \mathrm{M}_{\mathrm{r}}+\sum_{\mathrm{r}=1}^{\mathrm{p}-1} \mathrm{z}_{\mathrm{ar}}-\sum_{\mathrm{i}=1}^{\mathrm{p}} \mathrm{M}_{\mathrm{i}}$

$\mathrm{M}_{\mathrm{b}}=$ Expected processing time of the first job on machine $\mathrm{M}$ in sequence $S_{i}$

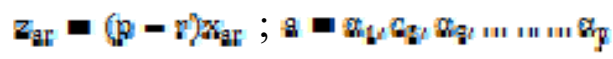

The sequence with minimum total waiting time is the required optimal sequence.

\section{NUMERICAL ILLUSTRATION}

Let 5 jobs $1,2,3,4,5$ are processed in a string $s$ on two machines $\mathrm{M} \& \mathrm{~N}$. Let the processing time matrix be seen as given below:

\begin{tabular}{|c|c|c|c|c|}
\hline Job & \multicolumn{2}{|c|}{ Machine M } & \multicolumn{2}{c|}{ Machine N } \\
\hline $\mathbf{I}$ & $\mathbf{M}_{\boldsymbol{i}}$ & $\mathbf{s}_{\boldsymbol{i}}$ & $\mathbf{N}_{\mathbf{i}}$ & $\mathbf{t}_{\boldsymbol{i}}$ \\
\hline 1. & 3 & 0.3 & 6 & 0.2 \\
\hline 2. & 5 & 0.2 & 8 & 0.2 \\
\hline 3. & 6 & 0.1 & 6 & 0.3 \\
\hline 4. & 2 & 0.3 & 7 & 0.2 \\
\hline 5. & 2 & 0.1 & 12 & 0.1 \\
\hline
\end{tabular}

Table 4

Our objective is to obtain optimal sequence of jobs minimizing the total waiting time for the jobs by taking 3,5 as a group job $(3,5)$

\section{Solution}


As per step 1- Define new expected processing time $\mathrm{M}_{j} \& \mathbb{N}_{j}$ on machine $M \& \&$ respectively as shown in the following table

\begin{tabular}{|c|l|l|}
\hline Job & \multicolumn{1}{|c|}{ Machine M } & \multicolumn{1}{|c|}{ Machine $\mathbf{~}$} \\
\hline $\mathbf{I}$ & $\mathbf{M}_{\mathbf{i}}$ & $\mathbf{N}_{\mathbf{i}}$ \\
\hline 1. & 0.9 & 1.2 \\
\hline 2. & 1.0 & 1.6 \\
\hline 3. & 0,0 & 1.8 \\
\hline 4. & 0.6 & 1.4 \\
\hline 5. & 0.2 & 1.2 \\
\hline
\end{tabular}

Table 5

$\operatorname{Max} \mathrm{M}_{\mathrm{i}}=1,0 \subseteq \operatorname{Min} \mathrm{N}_{\mathrm{i}}=1.2$

As per step 2- Take equivalent job $a=(3,5)$. The processing times are defined as follows

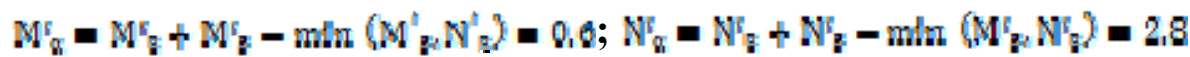

\begin{tabular}{|c|c|c|c|}
\hline Job & $\begin{array}{c}\text { Machine } \\
\mathbf{M}\end{array}$ & $\begin{array}{c}\text { Machine } \\
\mathbf{N}\end{array}$ & \\
\hline $\mathbf{I}$ & $\mathbf{M}_{\mathrm{i}}$ & $\mathbf{N}_{\mathrm{i}}$ & $\mathbf{x}_{1}-\mathbf{N}_{\mathrm{i}}-\mathbf{M}_{\mathrm{i}}$ \\
\hline 1. & 0.9 & 1.2 & 0.3 \\
\hline 2. & 1.0 & 1.6 & 0.6 \\
\hline$a$. & 0.6 & 2.8 & 2.2 \\
\hline 4. & 0.6 & 1.4 & 0.8 \\
\hline
\end{tabular}

Table 6

As per step 3- Arrange the jobs in increasing order of $x_{i}$ i.e. the sequence found be $1,2,4, a$.

As per step 4- $M M_{m}\left\{M_{i}\right\}=0,6=M_{i}$

As per step 5- Consider the following different sequences of jobs

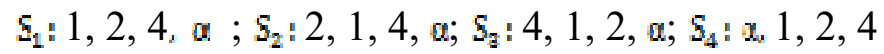

As per step 6- Fill up the values in the following table

\begin{tabular}{|c|c|c|c|c|c|c|c|}
\hline Job & Machine M & Machine & & $z_{1 t}=1$ & $r^{n} / x_{1}$ & & \\
\hline I & $\mathbf{M}_{i}$ & $\mathbf{N}_{\mathbf{1}}^{*}$ & $x_{1}=N_{1}-M_{1}$ & $r=1$ & $r=2$ & $r=3$ & $r=4$ \\
\hline 1. & 0.9 & 1.2 & 0.3 & 1.2 & 0.9 & 0.6 & 0.3 \\
\hline 2. & 1.0 & 1.6 & 0.6 & 2.4 & 1.8 & 1.2 & 0.6 \\
\hline 3. & 0.6 & 1.8 & 1.2 & 4.8 & 3.6 & 2.4 & 1.2 \\
\hline 4. & 0.6 & 1.4 & 0.8 & 3.2 & 2.4 & 1.6 & 0.8 \\
\hline 5. & 0.2 & 1.2 & 1.0 & 4.0 & 3.0 & 2.0 & 1.0 \\
\hline
\end{tabular}

Table 7

As per step 7- Calculate the total waiting time for the sequences $s_{1}, s_{2}, s_{9} s_{4}$. 
For this problem $\Sigma_{-1} \mathrm{M}_{\mathrm{i}}=3.3$

For the sequence $S_{1: 1,2,4, \varepsilon}$ or $S_{\mathbb{1}, 1,2,4,8}$

$\alpha_{1}=11, \alpha_{2}=2, \alpha_{9}=4, \alpha_{4}=3, \alpha_{8}=3$

Hence total waiting time $\mathbb{T}_{w} \boldsymbol{\pi} \pi, 0$

For the sequence $S_{2}: 2,1,4, a$ or $S_{2}: 2,1,4,3,5$

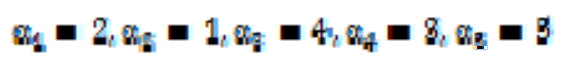

Total waiting time $\mathbb{T}_{w} \mathbf{\pi} \pi, 8$

For the sequence $S_{2}: 4,1,2, \alpha$ or $S_{3}: 4,1,2,3,5$

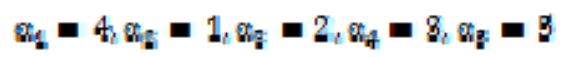

Total waiting time $\mathbb{T}_{w} \boldsymbol{\bullet} \boldsymbol{\Omega}, 2$

For the sequence $S_{4}: 1,2,4$ or $S_{4}: 3,5,1,2,4$

$\omega_{4}=8, \alpha_{2}=3, \alpha_{3}=1, \alpha_{4}=2, \alpha_{z}=4$

Total waiting time $\mathbb{T}_{w} \mathbf{8} 8, \overline{7}$

Hence schedule $\mathrm{s}_{4}: 4,1,2, \alpha$ or $\mathrm{s}_{4}: 4,1,2,3,5$ is the required optimal schedule with $(3,5)$ as a group job.

\section{CONCLUSION}

The present study deals with the flow shop scheduling problem with the main idea to minimize the total waiting time of jobs. However it may increase the other costs like machine idle cost or penalty cost of the jobs, yet the idea of minimizing the waiting time may be an economical aspect from Factory /Industry manager's view point when he has minimum time contract with a commercial party to complete the jobs. The work can be extended by introducing various parameters like transportation time, break down interval etc.

\section{REFERENCES}

[1] Johnson, "Optimal two and three stage production schedule with set up times included," in Nay Res Log Quart Vol. 1, 1954, pp. 61-68.

[2] Ignall, E. and Schrage, L.E., "Application of branch and bound techniques to some flow shop problems," in Operation Research 13, 1965, pp. 400-412.

[3] Lockett, A.G. and Muhlemann, A.P., "Technical notes: a scheduling Problem involving sequence dependent changeover times," in Operation Research 20, 1972, pp. 895- 902.

[4] Maggu P.L. and Dass G., "Equivalent jobs for job block in job sequencing," in Operations Research, Vol.14, No. 4, 1977, pp. 277-281.

[5] Singh T.P., "On $\mathrm{n} \times 2$ shop problem involving job block, transportation times and Break-down Machine times," in PAMS Vol.XXI, No.1-2, 1985. 
[6] Gupta, J.N.D., "Flow shop schedules with sequence dependent setup times," in Journal of the Operations Research Society of Japan 29, 1986, pp.206-219.

[7] Rajendran, C. and Chaudhuri, D., "An efficient heuristic approach to the scheduling of jobs in a flow-shop," in European Journal of Operational Research 61, 1992, pp.318- 325.

[8] Singh T.P., Gupta D. and Kumar R., "Optimal two stage production schedule with Group jobrestrictions having set up times separated from processing time associated with probabilities," in Reflections des ERA, (JMS) Vol. I, 2006, pp. 53-70.

[9] Singh T.P., Gupta D. \& Kumar R., "Bi-criteria in scheduling under specified rental policy, processing time associated with probabilities including job block concept," Presented at National Conference on information technology at NCCEI, March 18-20, 2006

[10] Narrain L., Gupta D. \& Kumar R. , "Minimization rental cost under specified rental policy in two stage flow shop the processing times associated with probabilities including job block criteria," in Reflections des ERA, (JMS) Vol. 2, 2006, pp. 107-120.

[11] Singh V., "Three machines flow shop scheduling problems with total rental cost," in International referred journal, Vol.-II, Jan 2011, pp.79-80.

[12] Gupta D., "Minimizing rental cost under specified rental policy in two stage flow shop, the processing time associated with probabilities including break down interval and job block criteria," in European Journal of Business and Management (USA), Vol.3, No.2 , 2011, pp. 85103.

[13] Gupta D. \& Goyal B., "Optimal scheduling for total waiting time of jobs in specially structured two stage Flow Shop Scheduling with processing times associated with probabilities," in Aryabhatta Journal of Mathematics \& Informatics, Vol.8, No. 1, Jan- June 2016, pp. 45-52. 